\title{
The Analysis of Reasonableness and Feasibility of Resource-conserving Coal Project Cost
}

\author{
Congcai Wang \\ Jiangsu Jianzhu Institute, Xuzhou, 221116, China
}

Keywords: Conservation. Cost. Coal projects. Analysis

\begin{abstract}
We need to analyze the reasonableness and efficiency of the energy industry from many aspects. Resource-conserving cost is a new industrial conception occurred under the concept of energy conservation and environmental protection. For coal projects, the modern management concept and digging management measures should be taken to achieve the conserving control of the coal projects through specific ways. The passage explores the reasonableness and the practical measures through the analysis of coal projects costs in the field of economics and engineering.
\end{abstract}

\section{Introduction}

Energy industry is one of the important industries and the use and sustainable exploration of energy is the trend of future. Among energy industries, coal is one of the important energies. So, coal exploration projects should satisfy the concept of environmental protection and resource conversation. We should adopt the way of conversation to mine the coal to fully exploit the energy and improve efficiency. Then, how can we reach the reasonableness of coal project during the process of coal mining? How to achieve conserved coal project has become the topic worth discussing in energy industry. The passage studies the reasonableness and the way how to reach it of conserving coal projects costs through the analysis of costs of the coal projects.

\section{The conceptual analysis of coal projects costs}

Energy industry is an unsustainable industry. For coal, it will run out one day, then will never exist. Though, there are a lot of resources around the world, with the increase of population and the demand for energy, we now should consider using the concept of energy conservation and environmental protection. Especially in the field of coal mining, we should apply the concept of conservation. So, how do we understand the conserving coal projects? During the process of understanding, what definitions and conceptions should we specify? I will analyze the following questions and explore the costs of conserving coal projects.

\section{The Conceptual Analysis of the Costs of Conserving Coal Projects}

Costs belong to the category of economics. As the use of engineering exploration projects during the process of coal mining, we should also analyze from the point of economics to define the definition of costs. Cost is an economic definition for a project, whose all expenses can be called cost. In fact, to put it simple, cost is the expense of a project. With the more frequent use of energy and the less total storage capacity, the concept of resource conversation and environmental protection becomes deepened in our heart. At present, many industries began the conserving production and saving exploit project, aiming to reach the conserving project more effectively and the energy-conservation and environmental protection. In the respect of cost, economics can also introduce the concept of conservation. Cost is an estimation of a project. The conserving cost concept can be analyzed from the point of economics, ensuring the effective use of the expenses. High cost has little influence on the project's quality. As long as tighten the expense in economy, we can ensure the quality in the field of project. The conserving cost combines engineering with economics, which finally aims to achieve the concept of energy-conversation and environmental protection. 


\section{The Conceptual Analysis of Conserving Coal Project}

Coal projects are productions of the combination of production, exploit and transportation. From the point of engineering, coal project includes many aspects, which aims to conduct the comprehensive and integrated exploit and production of coal. Coal projects belong to formal exploiting institute, including the managers, production team, the constructing workers under well and the supervising engineers, etc. As a result, coal project is an integral team focusing on the exploit and production, which to some extent can decide the efficiency of the coal production. Furthermore, with the deepening of the concept of energy conservation, the coal industry has been influenced. From the point of the conserving coal project, it emphasized the concept of energy conservation and environmental protection, improving the efficiency to the best while making the expenses to the least during the process of the exploit and mining of coal project. In fact, the mining of coal should ensure the full use of coal. The traditional exploit mode of coal project lacks efficiency in the use of coal and there is waste of the coal. During the process of transportation, it easily causes the loss of transportation. In addition, there is self-ignition and weathering, which causes the waste of coal. So, we should analyze the conserving coal project from many aspects. We should not only make the expense of the whole project achieve the goal of energy conversation, but also reach conservation in the storage and transportation of coal. As a result, the conserving coal project is a comprehensive question from both engineering and economics.

\section{The Analysis of Reasonableness of Conserving Coal Project}

We analyze the conserving coal project from many aspects through the analysis of the concept of conserving coal project, further discussing the two concepts in economics and engineering. But, how can it ensure the reasonableness of the cost of the conserving coal project from the point of reasonableness? Can we make it effective in practice?

\section{The Analysis of Reasonableness of Coal Project from the Point of Economics}

Cost is a concept from the point of economics. We should analyze the expense and construction to study the cost of coal project. Then, we should analyze the reasonableness of the cost of conserving coal project from the point of economics.

Firstly, the total cost of coal project matters the benefits of coal business. The development of business must base on the profits. If the cost is high and there is no basis of enough profit, problems will occur, which will cause the irrelevance between market and industry. So for the analysis of cost, we should analyze the practical industry. For coal industry, especially the energy industry, the profit is high. While there may be general exploit and investment in expense. There often be the general investment and cash flow during the process of capital investment and use of capital. In the aspect of managing staff, there is corruption or freeloading. Therefore, during the process of the analysis of cost of coal project, we should make economic idea as an basis, ensuring the long term development. The coal industry belongs to energy industry, which should abide by the market rule under the condition of market economy, ensuring the occupation rate of market.

Secondly, the cost of coal should consider the rate of expense and income, which can't be achieved because of the unique of the energy industry. Consequently, when we consider the reasonableness of conservation, we should abide by the market rule under the background of whole market. For some listed business, the element of production is not the only element affecting market value. For enterprises, they should improve the value from lots of aspects. Presently, many sectors have complete managing system. So, the reasonableness should consider the whole market, ensuring a position in the market for it.

Finally, the reasonableness of cost of economics is estimated from the whole coal project through the analysis of the whole expense and production of coal project to define the total cost. As coal industry should consider the safety of constructing workers, we should comprehensively consider the coast. 


\section{The Analysis of Reasonableness of Coal Project from the Point of Engineering}

The expenses of coal project mainly focus on the exploit and later storage of coal from the point of engineering. The exploit of coal adopts the modern mechanicals and equipment, ensuring the quality and efficiency of coal. The coal is closely connected with the project. So we should improve the efficiency of exploit to achieve the goal of putting little while getting a lot. Besides, the modern transportation equipment should be used for transportation, ensuring the least loss of coal during the process of transportation. And , as for the characteristic of coal, there will be self-ignition during the process of storage, causing the loss of coal. We should consider how to achieve the energy conservation and environmental protection of the transportation and storage from the point of engineering. As a result, we should reach the reasonableness of the coal project from the view of engineering to meet the concept of energy conservation and environmental protection.

\section{The Analysis of the Measures to Achieve Conserving Coal Project}

The reasonableness of cost of conserving coal project is doubtless. But what measures can we take to achieve the reasonableness of coal project. Which specific measures should we take to make the reasonableness?

Firstly, we should conduct from the whole staff and management from the economics of coal project. Such as, we should equip project supervising workers during the process of construction to ensure safety and improve efficiency. As there is some problems concerning safety during the process of construction, we must supervise to avoid the accidents. In many coal projects, it lacks enough supervision. The lack of supervision can easily cause the lying problem of the project. Once there will be safety problem, it will cause great loss. Therefore, we should reasonably arrange the staff, ensuring the safety of the project. But, for many arrangement of the department, we should simplify. While we should conduct effective management of some important departments, such as we should have high quality staff in the management of financial department, reaching the effective management of finance and the simplification of the coal project.

Secondly, we should analyze the exploit, transportation and storage from the point of engineering, achieving the modern exploit to reduce the number of staff. In addition, we use train to transport, ensuring the high efficiency of transportation and shorten the time. Meanwhile, the storage and storage method should be effective and scientific, reducing the self-ignition of coal and the loss of coal resulted from the reduce of the number of staff.

All in all, in the aspect of measure, we should take the concept of cenergy conservation and environmental protection to achieve the conserving use of coal from the point of engineering and economics to reach the modern conserving coal project.

\section{Conclusion}

We have an effective study of the reasonableness of coal project from the point of economics and engineering. In order to truly achieve the conservation of coal, ensuring the effective use of expense and output, we should analyze from the aspect of staff management, coal transportation, loading and storage to perfect the nature of project and ensure the accuracy of the development orientation. In addition, in the reasonable study, we should understand economics and engineering to have a comprehensive study. The specific measures should be analyzed from many points to finally achieve the reasonableness and effect of the cost of coal project.

\section{References}

[1] Xu Binbin, Ye Bailong, Lulan: Synchronized Methods of HDB Based on J2EE, Microcomputer Information, 2011(07): 205-206

[2] Yang Changdong: The Study of Ventilation Technology and Safety Management of the Exploit Project in the Highly Gas Mine, Value Engineering, 2013(16); 104-105 
[3] Zhao Xingyu, Wangwei, Dai Xionghui, Bi Fenfen: The Application of SLOPE/W in the Slope Stability of a Certain Open Pit, .Journal of Water Resources and Architectural Engineering, 2013(01): 187-191 